Check for updates

Cite this: Mater. Chem. Front., 2020, 4, 1289

Received 30th October 2019 Accepted 29th December 2019

DOI: $10.1039 / c 9 q m 00674 \mathrm{e}$

rsc.li/frontiers-materials

\title{
The application of hollow micro-/nanostructured cathodes for sodium-ion batteries
}

\author{
Xiao-Hao Liu, (D) ${ }^{a}$ Wei-Hong Lai ${ }^{b}$ and Shu-Lei Chou (D) $* a b$
}

\begin{abstract}
High-performance sodium-ion batteries (SIBs) rely on efficient cathodes, constructed based on advances in excellent rate capability, high capacity, and small volume change. Cathode materials with micro-/ nano-hollow architectures can shorten the diffusion length, offer volume buffering, and increase the conducting capability of electrons/ions, so they have been extensively developed as a new strategy for the exploration of future cathodes. This review offers a snapshot of the recent progress on the synthetic strategies used to prepare hollow cathodes, their improved battery performance, and the mechanism of sodium storage underlying the use of hollow micro-/nanostructured cathode materials. Finally, we provide an overview of likely future directions in this research, which includes seeking the right balance between volumetric capacity and energy density.
\end{abstract}

\section{Introduction}

Recently, sodium-ion batteries (SIBs) have emerged as the most promising candidates for next-generation commercial energy storage systems due to the abundance of sodium resources, and the low cost and environmental-friendliness of sodium as a raw material. ${ }^{1-5}$ Many efforts have been made to develop highperformance sodium ion storage systems with high-safety, high energy density, excellent rate capability, and long cycling life. The cathode materials play a crucial role in SIBs, but the ones currently available are still challenging for real use, owing to

\footnotetext{
${ }^{a}$ School of Environmental and Chemical Engineering, Shanghai University, 99 Shangda Road, Shanghai, 200444, P. R. China

${ }^{b}$ Institute for Superconducting \& Electronic Materials, University of Wollongong, Innovation Campus, Wollongong, NSW 2500, Australia.

E-mail:shulei@uow.edu.au
}

their poor electronic/ionic conductivity and drastic volume changes during sodiation/desodiation, as well as their slow ion diffusion caused by larger particles. ${ }^{6-8}$ In order to address the above problems, several strategies have been investigated, including nanosizing the cathode materials, carbon coating, and metal ion doping. ${ }^{9-12}$ Nanoengineering cathode materials is of high significance for enhancing the cycling stability and rate capability, as the ultrathin shell and high active surface area of hollow micro-/nanostructures can accelerate the ion transport between the layers, improve the ion adsorption, and feature faster surface redox reactions. ${ }^{13-15}$ Also, the construction of hollow micro-/nanostructures offers great "breathability", large void space, and better mono-dispersity, which are very crucial to address the issues arising from the volume changes. ${ }^{16}$ For example, Huang et al. reported hollow $0.3 \mathrm{Li}_{2} \mathrm{MnO}_{3}$. $0.7 \mathrm{LiNi}_{0.5} \mathrm{Mn}_{0.5} \mathrm{O}_{2}$ microspheres that displayed far better rate

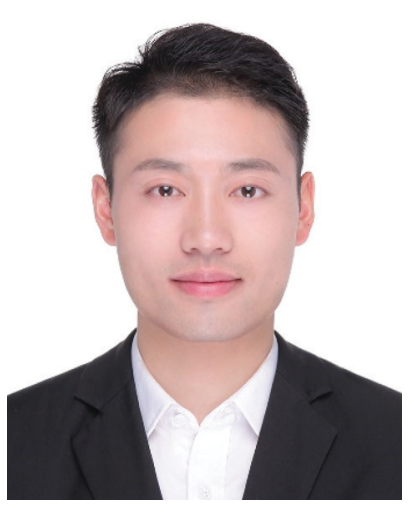

Xiao-Hao Liu
Xiao-Hao Liu received his MS degree from Shanghai University of Electric Power in 2019. Currently, he is a $\mathrm{PhD}$ candidate at the School of Environmental and Chemical Engineering, Shanghai University (SHU). His research interest is focused on the design and synthesis of advanced electrode materials for sodium-ion batteries.

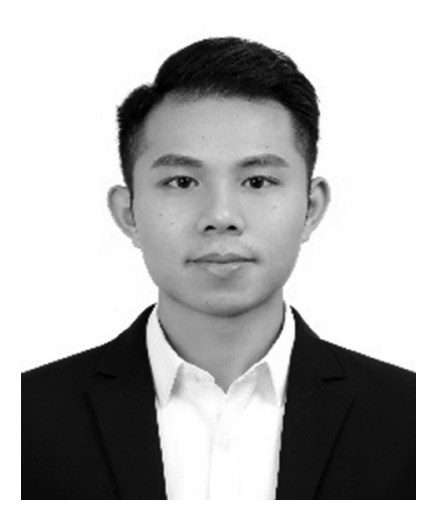

Wei-Hong Lai received his PhD degree from the Institute for Superconducting and Electronic Materials (ISEM), University of Wollongong (UOW) in 2019. His current research interest is renewable energy storage and conversion, including electrocatalysis, and lithium-air battery/ sodium-sulfur batteries. 


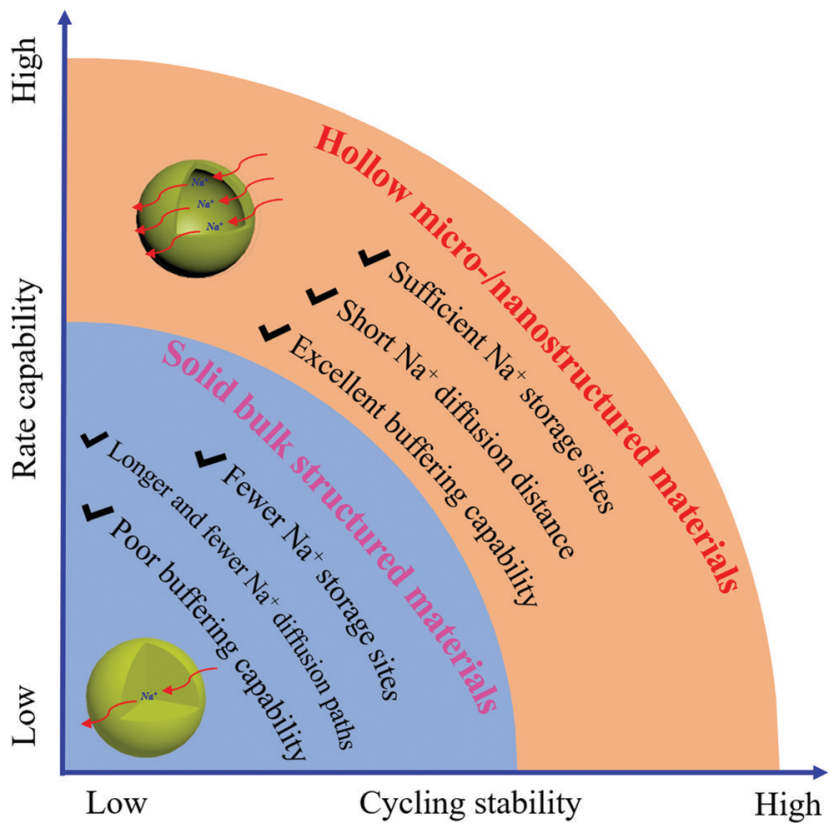

Fig. 1 Comparison of hollow micro-/nanostructured and solid bulk structured materials.

capability and cyclability than their bulk solid particle counterpart due to the merits of hollow micro-/nanostructures. ${ }^{17}$ As shown in Fig. 1, these hollow micro-/nanostructures with cavities and void space can dramatically enhance the rate capability and cycling stability of electrodes due to having sufficient ion storage sites, short ion diffusion lengths, large contact area of the active materials with the electrolyte, and the reversible accommodation of large volume changes. In contrast, their corresponding bulk structures demonstrated inferior electrochemical performance, owing to their having fewer ion storage sites and longer ion diffusion paths as well as poor buffering capability. More research results have vitrified this; for instance, Cao et al. compared hollow micro-/nanostructured $\mathrm{LiNi}_{1 / 3} \mathrm{Co}_{1 / 3} \mathrm{Mn}_{1 / 3} \mathrm{O}_{2}$ and its bulk structure, finding that the rate and cycling performance of the former was more excellent than the latter which benefited from the reducing path of $\mathrm{Li}$ ion diffusion, increasing contact area between electrodes and electrolyte and

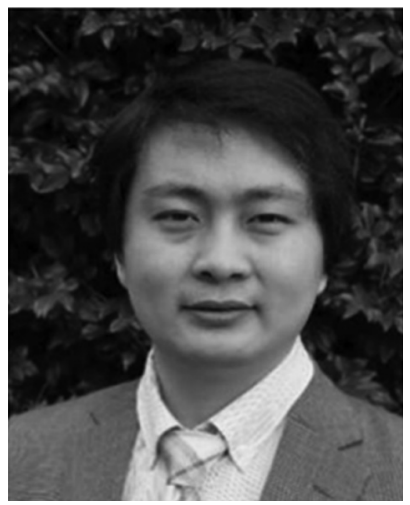

Shu-Lei Chou is currently an associate professor at the Institute for Superconducting and Electronic Materials, University of Wollongong. He received his $\mathrm{PhD}$ degree from the University of Wollongong in 2010. His research interests include energy storage materials for battery applications, especially novel composite materials, new binders, and new electrolytes for Li/Na batteries. buffering of the volume changes during the Li ion intercalation/ deintercalation processes. ${ }^{18}$ The rational design of hollow micro-/ nanostructured cathode materials and understanding their electrochemical mechanisms, thus, are beneficial for the improvement of the electrochemical performance of SIBs. Notably, the tap density of hollow micro-/nanostructured electrode materials will cause low volumetric energy density, which would limit their practical applications. ${ }^{19}$ Therefore, finding a way to find the right balance between the excellent electrochemical performance of hollow cathodic electrodes in SIBs and their modest volumetric energy density is very important. For hollow cathode materials, designing multi-shell structures may achieve higher volumetric energy density than its single-shell counterpart due to the utilization of the inner void. In this regard, Wang's group has contributed a lot of work on the illustration of the unique advantages of multi-shell hollow structured electrode materials, including LIBs and SIBs. ${ }^{20-22}$

Great attention has been devoted to designing hollow micro-/nanostructured anodes for SIBs ${ }^{23-26}$ but in the case of cathodes, there are no special reviews summarizing their progress. Herein, we summarize recent progress in the development of hollow-structured cathodes for SIBs by presenting the design strategies for the fabrication of hollow-structured cathodes and their application in SIBs. The mechanisms underlying their high electrochemical performance are also discussed in this review. Finally, a brief outlook on the future trends and challenges in this area is presented.

\section{Synthesis of hollow micro-/nanostructured materials}

Generally, hard-templating, soft-templating, sacrificial-templating, and template-free methods have been widely applied in the fabrication of electrode materials with hollow micro-/nanostructures. The hard-templating method has been commonly used for preparing hollow cathodes. Typically, some prepared particles need to be used as the "hard" core templates and are coated with the targeted materials or precursors. The core will then be removed via etching or thermal decomposition, and the shell layer will be retained to form a hollow structure. Polymers, silica, and carbon colloidal spheres are commonly employed as hard templates to construct hollow structures. ${ }^{27}$ The hard-templating method as a conventional strategy to construct hollow micro-/nanostructures due to its unique advantages of universality and easy-controlling size distribution. Nevertheless, the hard-templating route often needs toxic reactants, multiple steps and time-consuming processes to remove the template. The soft-templating method has attracted the greatest attention and significant progress has been made in the past decade due to the merits of flexibility, and time-saving. This method can be explained as the direct generation of hollow structures through the self-assembly of some structure guiding agents, such as surfactants or certain organic additives. As for the soft-templating method, the corresponding templates are rather easy to remove, but the morphology of the as-prepared hollow materials is usually not uniform because of their high 
sensitivity to the reaction conditions. What is more, the deformability and the dynamics of soft templates leads to poor monodispersity. ${ }^{28}$ Thus, it is of great significance to develop more efficient and simpler sacrificial-templating synthesis methods to prepare hollow micro-/nanostructures. The sacrificial-templating method refers to the formation of hollow micro-/nanostructures arising from the self-sacrifice of in situ formed template without the use of a pre-existing template in the reaction process. ${ }^{29,30}$ Similar to traditional hard templates, the shape and cavity size of the obtained hollow micro-/nanostructures can be directly determined by sacrificial templates, whereas the template can also play the role of a structure-directing scaffold and precursor for the shell. ${ }^{31}$ Thus, a sacrificial-templating method is inherently advantageous because it generally does not need additional surface functionalization and ensures the shell formation via a chemical reaction. In this regard, the preparation process of hollow micro-/nanostructures by this method is therefore typically more efficient. Conventional ways to fabricate hollow micro-/nanostructures generally require various pre-synthetic templates including a hard template, soft template and sacrificial template, which results in a high cost of template materials and the complexity of multi-step synthetic procedures. ${ }^{32}$ Thus, exploring template-free methods for the preparation of hollow micro-/ nanostructures is of interest and remains challenging. The template-free method means that no template is required in the preparation process, and the formation mechanism can be explained by an oriented aggregation of nanoparticles selfassembling into the hollow micro-/nanostructure, such as insideout Ostwald ripening, the Kirkendall effect and the oriented attachment process. $^{33,34}$ Recently, template-free hydrothermal/ solvothermal route and spray pyrolysis have been regarded as highly efficient and facile strategies to prepare hollow micro-/ nanostructured electrode materials, and are easy to scale-up. ${ }^{35-37}$ Fig. 2 summarizes the construction methods and their advantages and disadvantages of hollow micro-/nanostructures for different kinds of cathode materials.

\section{Sodium cathodes based on hollow micro-/nanostructured materials}

Recently, many researchers have focused their attention on morphology control in energy storage materials, which is expected to significantly improve the electrochemical performance of electrode materials. Hollow micro-/nanostructures have been widely applied in cathode materials for lithium-ion batteries (LIBs), which have been regarded as effective approaches to enhance their Li storage performance. ${ }^{17,38-40}$ For example, due to the inferior electrochemical reaction kinetics of SIBs compared to LIBs, designing unique hollow structured electrodes is more essential for accelerating the migration of $\mathrm{Na}^{+}$ions and thus achieving superior $\mathrm{Na}$ storage capability. Cathode materials with hollow micro-/nanostructures have attracted considerable attention for increasing the electrochemical performance of LIBs. Although they have benefited from this research, cathode materials for SIBs with hollow characteristics still need to be

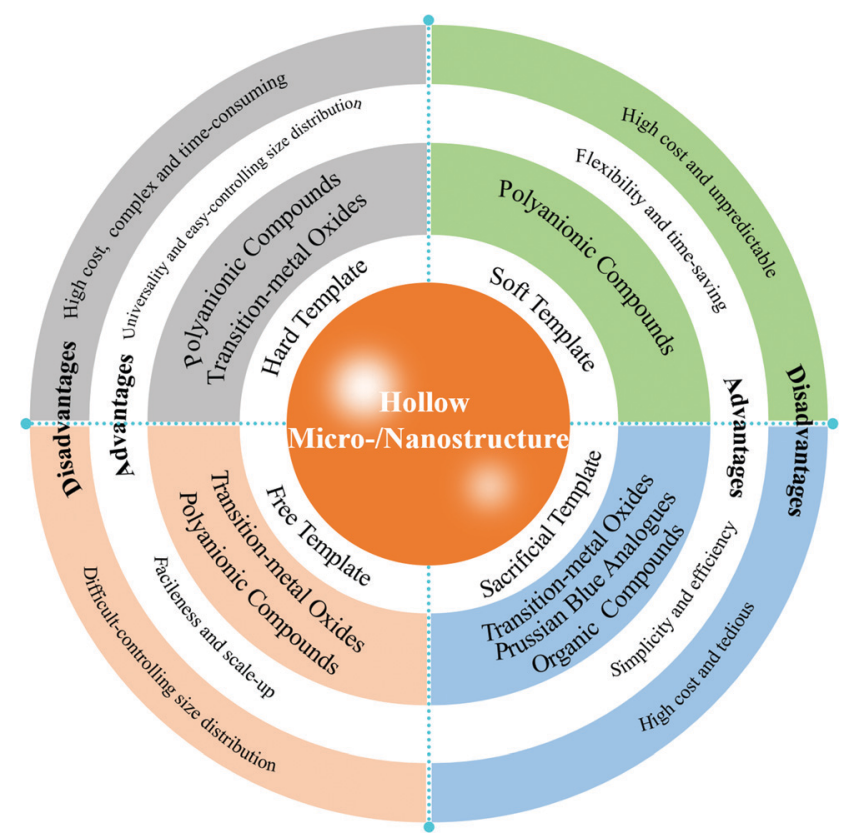

Fig. 2 Construction methods, advantages and disadvantages of hollow micro-/nanostructures for different kinds of cathode materials.

thoroughly explored. This work has motivated us to exploit the Na storage performance of different kinds of cathodes with hollow micro-/nanostructures. As summarized in Table 1, numerous studies about the utilization of hollow micro-/nanostructures as sodium-ion battery cathodes have been reported in recent years. In this part, we illustrate a variety of hollow micro-/nanostructured cathode materials that have been successfully used for SIBs, including transition-metal oxides, polyanionic compounds, Prussian blue analogues, and organic compounds.

\subsection{Transition-metal oxides}

Transition-metal oxides are the most studied cathodes owing to their high theoretical capacity and working voltage. The structure of transition metal oxides is unstable, however, which results in poor cycling stability. ${ }^{41-44}$ Hollow micro-/nanostructured electrodes with large interior free volume can alleviate the structural strains associated with repeated $\mathrm{Na}^{+}$ion insertion/extraction processes, leading to better structural and cycling stability. Thus, constructing hollow micro-/nanostructures for achieving transition-metal oxides with high performance is a good choice. In the case of the transition-metal oxides, hollow micro-/nanostructures can be achieved by hard-templating, sacrificial-templating, and template-free methods.

Zheng et al. prepared VOOH hollow microspheres with low crystallinity by a template-free hydrothermal route, and found that VOOH used as a cathode for SIBs exhibited outstanding rate performance and long cycle life. ${ }^{45}$ The low crystallinity and hollow microspherical structure of $\mathrm{VOOH}$ contributed to its outstanding performance, which could avoid unfavorable multiple phase transitions and alleviate the strains that appear during the insertion/extraction of $\mathrm{Na}^{+}$ions. Furthermore, Wang's group constructed $\mathrm{V}_{2} \mathrm{O}_{5}$ hollow nanospheres via a template-free 
Table 1 Summary of recent progress on the material synthesis and electrochemical performance of hollow micro-/nanostructured cathodes

\begin{tabular}{|c|c|c|c|c|c|c|}
\hline Hollow cathodes & Morphology & Synthesis method & $\begin{array}{l}\text { Capacity } \\
\left(\mathrm{mA} \mathrm{h} \mathrm{g}^{-1}\right)\end{array}$ & $\begin{array}{l}\text { Rate capability } \\
\left(\mathrm{mA} \mathrm{h} \mathrm{g}^{-1}\right)\end{array}$ & $\begin{array}{l}\text { Cycling performance } \\
\left(\mathrm{mA} \mathrm{h} \mathrm{g}^{-1}\right)\end{array}$ & Ref. \\
\hline VOOH & Microsphere & Free template & $150 / 0.02 \mathrm{~A} \mathrm{~g}^{-1}$ & $84 / 0.3 \mathrm{~A} \mathrm{~g}^{-1}$ & $126 / 200 \mathrm{th} / 0.04 \mathrm{~A} \mathrm{~g}^{-1}$ & 45 \\
\hline $\mathrm{V}_{2} \mathrm{O}_{5}$ & Nanosphere & Free template & $\sim 150 / 0.02 \mathrm{~A} \mathrm{~g}^{-1}$ & $\sim 112 / 0.64 \mathrm{~A} \mathrm{~g}^{-1}$ & $141 / 100 \mathrm{th} / 0.02 \mathrm{~A} \mathrm{~g}^{-1}$ & 46 \\
\hline $\mathrm{K}_{0.27} \mathrm{MnO}_{2}$ & Nanosphere & Hard template & $83 / 0.2 \mathrm{~A} \mathrm{~g}^{-1}$ & $56.6 / 0.6 \mathrm{~A} \mathrm{~g}^{-1}$ & $68.7 / 100 \mathrm{th} / 0.2 \mathrm{~A} \mathrm{~g}^{-1}$ & 47 \\
\hline $\mathrm{Na}_{0.7} \mathrm{MnO}_{2.05} @ P P y$ & Nanosphere & Sacrificial template & $165.1 / 0.1 \mathrm{~A} \mathrm{~g}^{-1}$ & $100.5 / 2 \mathrm{~A} \mathrm{~g}^{-1}$ & $142.6 / 100 \mathrm{th} / 0.1 \mathrm{Ag}^{-1}$ & 48 \\
\hline $\mathrm{Na}_{3} \mathrm{~V}_{2}\left(\mathrm{PO}_{4}\right)_{3} / \mathrm{C}$ & Nanosphere & Free template & $106 / 11.8 \mathrm{~mA} \mathrm{~g}^{-1}$ & $84 / 47.2 \mathrm{~A} \mathrm{~g}^{-1}$ & $93 / 10000 \mathrm{th} / 118 \mathrm{~mA} \mathrm{~g}^{-1}$ & 60 \\
\hline $\mathrm{Na}_{3} \mathrm{~V}_{2}\left(\mathrm{PO}_{4}\right)_{3} / \mathrm{C}$ & Nanosphere & Free template & $\sim 100 / 0.02 \mathrm{~A} \mathrm{~g}^{-1}$ & $75.8 / 0.2 \mathrm{~A} \mathrm{~g}^{-1}$ & $89.3 / 300 \mathrm{th} / 0.02 \mathrm{~A} \mathrm{~g}^{-1}$ & 61 \\
\hline $\mathrm{NaFePO}_{4}$ & Nanosphere & Hard template & $152.1 / 15.5 \mathrm{~mA} \mathrm{~g}^{-1}$ & $67.4 / 1.55 \mathrm{~A} \mathrm{~g}^{-1}$ & $144.3 / 300 \mathrm{th} / 15.5 \mathrm{~mA} \mathrm{~g}^{-1}$ & 62 \\
\hline $\mathrm{Na}_{2} \mathrm{FePO}_{4} \mathrm{~F}$ & Nanosphere & Free template & $89 / 12.4 \mathrm{~mA} \mathrm{~g}^{-1}$ & $75 / 124 \mathrm{~mA} \mathrm{~g}^{-1}$ & $60 / 750 \mathrm{th} / 124 \mathrm{~mA} \mathrm{~g}^{-10}$ & 63 \\
\hline $\mathrm{Na}_{3} \mathrm{~V}_{1.95} \mathrm{Mn}_{0.05}\left(\mathrm{PO}_{4}\right)_{2} \mathrm{~F}_{3} @ \mathrm{C}$ & Microsphere & Free template & $122.9 / 25.6 \mathrm{~mA} \mathrm{~g}^{-1}$ & $60.7 / 1.28 \mathrm{~A} \mathrm{~g}^{-1}$ & $109 / 500 \mathrm{th} / 25.6 \mathrm{~mA} \mathrm{~g}^{-1}$ & 64 \\
\hline $\mathrm{Na}_{2} \mathrm{FePO}_{4} \mathrm{~F} / \mathrm{C}$ & Microsphere & Soft template & $120.1 / 12.4 \mathrm{~mA} \mathrm{~g}^{-1}$ & $65.2 / 0.62 \mathrm{~A} \mathrm{~g}^{-1}$ & 82.9/200th/124 $\mathrm{mA} \mathrm{g}^{-1}$ & 65 \\
\hline $\mathrm{Na}_{1.38} \mathrm{Ni}_{0.07} \mathrm{Mn}_{0.93}\left[\mathrm{Fe}(\mathrm{CN})_{6}\right]_{0.82} \cdot \square_{0.18} \cdot 1.4 \mathrm{H}_{2} \mathrm{O}$ & Nanocube & Sacrificial template & $123 / 0.05 \mathrm{~A} \mathrm{~g}^{-1}$ & $52 / 3.2 \mathrm{~A} \mathrm{~g}^{-1}$ & $102 / 600 \operatorname{th} / 0.05 \mathrm{~A} \mathrm{~g}^{-1}$ & 71 \\
\hline $\mathrm{Na}_{0.99} \mathrm{Mn}_{0.37} \mathrm{Fe}_{0.63}\left[\mathrm{Fe}(\mathrm{CN})_{6}\right]_{0.96} \cdot \square_{0.04} \cdot 1.36 \mathrm{H}_{2} \mathrm{O}$ & Rod-like & Sacrificial template & $117.3 / 0.1 \mathrm{~A} \mathrm{~g}^{-1}$ & $92.4 / 2 \mathrm{~A} \mathrm{~g}^{-1}$ & $109.2 / 300 \mathrm{th} / 0.5 \mathrm{~A} \mathrm{~g}^{-1}$ & 72 \\
\hline $\mathrm{Na}_{1.58} \mathrm{Fe}\left[\mathrm{Fe}(\mathrm{CN})_{6}\right]_{0.92}$ & Nanosphere & Sacrificial template & $142 / 17 \mathrm{~mA} \mathrm{~g}^{-1}$ & $76 / 1.7 \mathrm{~A} \mathrm{~g}^{-1}$ & $\sim 102 / 800 \operatorname{th} / 0.34 \mathrm{~A} \mathrm{~g}^{-1}$ & 73 \\
\hline Polyaniline & Nanofiber & Sacrificial template & $153 / 45 \mathrm{~mA} \mathrm{~g}^{-1}$ & $70 / 1.2 \mathrm{~A} \mathrm{~g}^{-1}$ & $\sim 66 / 1000 \mathrm{th} / 0.8 \mathrm{~A} \mathrm{~g}^{-1}$ & 77 \\
\hline Polypyrrole & Nanosphere & Sacrificial template & $97 / 0.02 \mathrm{~A} \mathrm{~g}^{-1}$ & $87 / 0.32 \mathrm{~A} \mathrm{~g}^{-1}$ & $77 / 100 \mathrm{th} / 0.04 \mathrm{~A} \mathrm{~g}^{-1}$ & 78 \\
\hline
\end{tabular}

polyol-induced solvothermal process. ${ }^{46}$ The $\mathrm{V}_{2} \mathrm{O}_{5}$ hollow nanospheres exhibited more outstanding electrochemical performance compared to solid $\mathrm{V}_{2} \mathrm{O}_{5}$ nanocrystals. Recently, Huang et al. used mono-dispersed nanospherical polystyrene (PS) as a hard template to prepare hollow $\mathrm{K}_{0.27} \mathrm{MnO}_{2}$ nanospheres as a cathode material for aqueous SIBs (Fig. 3a). ${ }^{47}$ Flowerlike core-shell structured PS@K- $\delta-\mathrm{MnO}_{2}$ spheres as intermediate products were obtained after a hydrothermal process. The PS template can be removed during the heating process to obtain the hollow $\mathrm{K}_{0.27} \mathrm{MnO}_{2}$ nanospheres. The $\mathrm{K}_{0.27} \mathrm{MnO}_{2}$ nanospheres are hollow and hierarchical structures composed of stacked multilayer nanosheets (Fig. $3 \mathrm{~b}$ and c). When the hollow $\mathrm{K}_{0.27} \mathrm{MnO}_{2}$ nanospheres were applied as a cathode, $\mathrm{NaTi}_{2}\left(\mathrm{PO}_{4}\right)_{3}$ as an anode, and $1 \mathrm{~mol} \mathrm{~L}{ }^{-1} \mathrm{Na}_{2} \mathrm{SO}_{4}$ aqueous solution as an electrolyte, their electrochemical performance in aqueous SIBs was investigated. Hollow $\mathrm{K}_{0.27} \mathrm{MnO}_{2}$ could achieve a discharge capacity of $56.6 \mathrm{~mA} \mathrm{~h} \mathrm{~g}^{-1}$ with the current density of $600 \mathrm{~mA} \mathrm{~g}^{-1}$, which represents outstanding high rate capability. Compared with the cycling performance of solid $\mathrm{K}_{0.27} \mathrm{MnO}_{2}$, the hollow $\mathrm{K}_{0.27} \mathrm{MnO}_{2}$ demonstrated a reversible discharge capacity of $68.7 \mathrm{~mA} \mathrm{~h} \mathrm{~g}^{-1}$ after 100 cycles (Fig. 3d). In contrast, only a low discharge capacity of $50 \mathrm{~mA} \mathrm{~h} \mathrm{~g}{ }^{-1}$ was observed at $200 \mathrm{~mA} \mathrm{~g}^{-1}$ for solid $\mathrm{K}_{0.27} \mathrm{MnO}_{2}$ nanoparticles (Fig. 3e), indicating that constructing hollow structured $\mathrm{K}_{0.27} \mathrm{MnO}_{2}$ is crucial for achieving great electrochemical performance. The improvement of their $\mathrm{Na}$ storage property can be ascribed to these three aspects: (i) a short ion diffusion distance exists due to the thin shell, and the inner void accelerates the migration of $\mathrm{Na}^{+}$ions; (ii) the large contact area between electrode and electrolyte ensures sufficient electrochemically active sites; and (iii) the stacked multilayer nanosheets increase the stability of the layered structure and lead to enhanced electronic conductivity, which is favorable for the charge transport and cycling stability of the electrode. Furthermore, Tu et al. showed a more direct comparison of the performances of solid and hollow electrodes. ${ }^{48}$ They fabricated hollow $\mathrm{Na}_{0.7} \mathrm{MnO}_{2.05}$ nanospheres (NMOHS) by using hollow $\mathrm{MnO}_{2}$ as the sacrificial template (Fig. 3f and g). In order to further enhance the electronic conductivity, the NMOHS were coated by polypyrrole (PPy) (Fig. 3h). As shown in Fig. 3i, the rate performances of hollow NMOHS@PPy and NMOHS exhibited more excellent rate capability than that of solid $\mathrm{K}_{0.7} \mathrm{MnO}_{2.05}$ microspheres (NMOSS). Also, the hollow NMOHS cathode demonstrated higher capacity retention of $72.7 \%$, compared to 35.6\% for the solid NMOSS cathode after 100 cycles (Fig. 3j). Furthermore, the NMOHS cathode delivered a discharge capacity of $72.5 \mathrm{~mA} \mathrm{~h} \mathrm{~g}^{-1}$ at $2 \mathrm{~A} \mathrm{~g}^{-1}$, whereas for the NMOSS cathode, the discharge capacity only remained at $29.6 \mathrm{~mA} \mathrm{~h} \mathrm{~g}^{-1}$ at the same current density. After the surface coating, the NMOHS@PPy cathode could reach $100.5 \mathrm{~mA} \mathrm{~h} \mathrm{~g}^{-1}$ at the same rate, much higher than for bare NMOHS. Thus, the construction of hollow micro-/nanostructures and PPy coating are crucial for the superior cycling stability and rate capability of the NMOHS@PPy cathode due to the enhanced conductivity and ideal contact area with the electrolyte.

To sum up, designing hollow micro-/nanostructures can shorten the $\mathrm{Na}^{+}$ion diffusion distance and increase the contact area of transition-metal oxide active materials with an electrolyte, thus the rate capability and cycling stability can be enhanced. What can't be ignored is that the decrease of volumetric energy density. Considering the advantage of high reversible capacity, it is still very meaningful to construct hollow micro-/nanostructures to boost the $\mathrm{Na}$ storage performance. In terms of practical application, multi-shelled hollow micro-/nanostructures can be a good choice.

\subsection{Polyanionic compounds}

In recent years, polyanionic compounds have received increasing attention and are expected to become promising cathode materials for SIBs owing to their structural stability. ${ }^{9,49-51}$ Nevertheless, their poor electronic conductivity and slow reaction kinetics lead to unsatisfactory rate performance and fast capacity decay, which severely restricts their practical applications. ${ }^{52,53}$ With the aim of overcoming these issues, hollow micro-/nanostructures can be a perfect electrode for shortening the diffusion distance of $\mathrm{Na}^{+}$ions to improve the rate capability and cycling stability. Hollow micro- $/$ nanostructured polyanionic compounds can be realized by hardtemplating, soft-templating, and template-free methods.

Recently, sodium superionic conductor (NASICON)-type $\mathrm{Na}_{3} \mathrm{~V}_{2}\left(\mathrm{PO}_{4}\right)_{3}$ (NVP), serving as representative of polyanionic compounds, has been intensively studied owing to its fast ion 


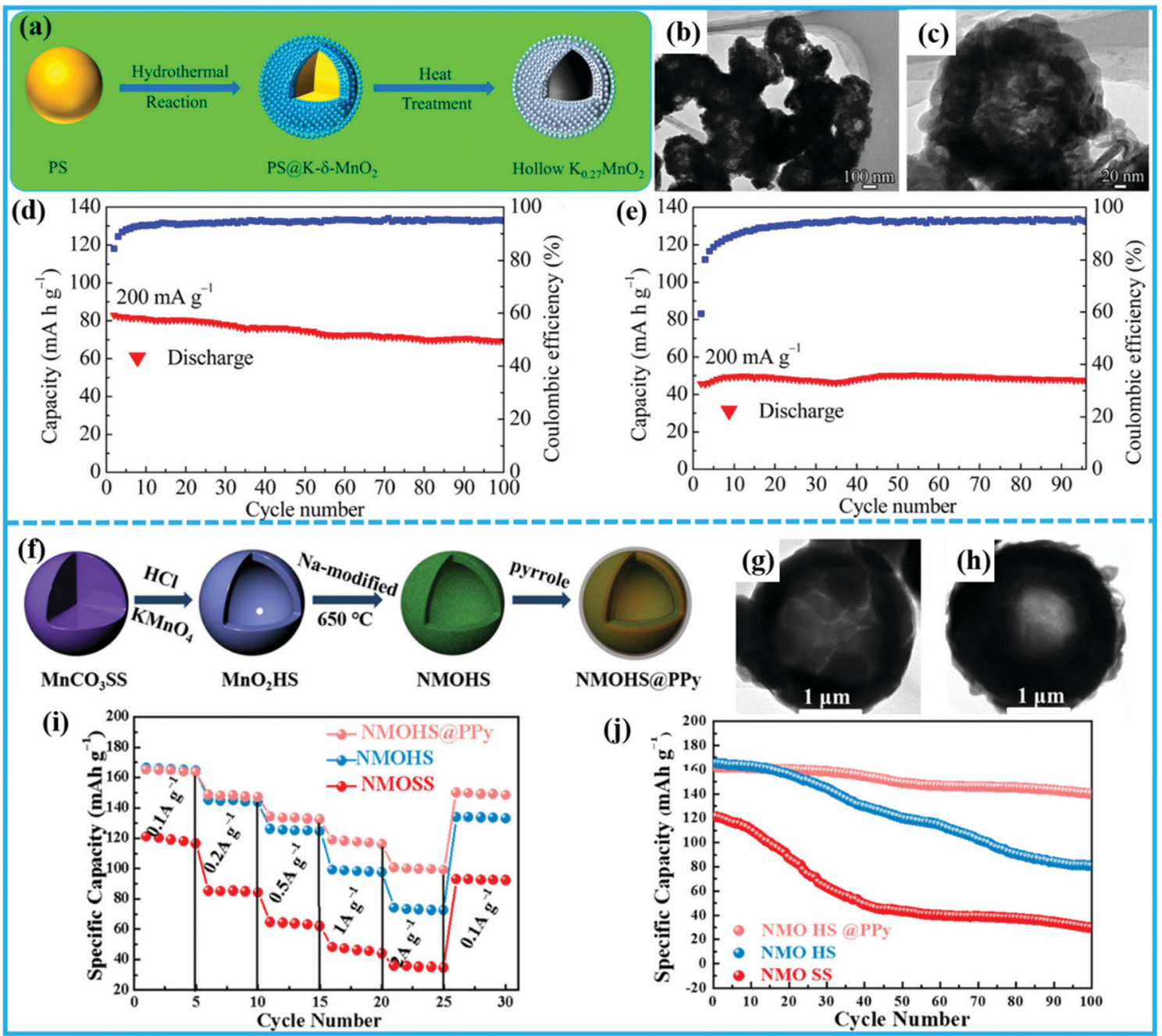

Fig. 3 (a) Schematic illustration of the fabrication of the hollow $\mathrm{K}_{0.27} \mathrm{MnO}_{2}$ nanospheres. (b and c) Transmission electron microscope (TEM) images of hollow $\mathrm{K}_{0.27} \mathrm{MnO}_{2}$, and cycling performances of hollow $\mathrm{K}_{0.27} \mathrm{MnO}_{2}$ (d) and $\mathrm{K}_{0.27} \mathrm{MnO}_{2}$ without a PS template (e) at a current density of 200 mA g ${ }^{-1}$. (Reprinted with permission from the American Chemical Society. Copyright 2016.) (f) Schematic illustration of the fabrication of NMOHS and NMOHS@PPy. TEM images of NMOHS (g) and NMOHS@PPy (h), and comparison with NMOSS of (i) their rate capabilities at 0.1, 0.2, 0.5, 1, and $2 \mathrm{~A} \mathrm{~g}^{-1}$, and (j) their cycling performances at $0.1 \mathrm{C} .{ }^{48}$ (Reprinted with permission from the American Chemical Society. Copyright 2019.).

diffusion capability and thermal stability. ${ }^{54,55}$ Unfortunately, it suffers from poor electronic conductivity and slow reaction kinetics, which significantly limit its electrochemical performance and further practical applications. ${ }^{6,56-59}$ The electronic conductivity of NVP can be improved through carbon coating, while designing hollow micro-/nanostructures can further enhance its overall performance. For instance, Wang' group reported three-dimensional (3D) NVP-based hollow porous nanospheres (3DHP-NVP@C) synthesized by a template-free method ${ }^{60}$ as shown in Fig. $4 a$ and b. When employed as a sodium ion cathode, this material displayed extraordinary high-rate performance and ultralong-cycling capability. Compared with the rate capabilities of 3DHP-NVP@C, NVP@C, and NVP, the 3DHP-NVP@C electrode presented the best Na storage properties in terms of both high capacity and high rate capability (Fig. 4c). The most attractive property of the 3DHPNVP@C was its excellent cycling stability at a high rate, achieving an ultralong cycling life of 30000 cycles under an ultrahigh rate of $50 \mathrm{C}$ with a capacity retention of over $80 \%$. In contrast, both the NVP and NVP/C electrodes showed rapid and large capacity losses (Fig. 4d). In general, the reasons why 3DHP-NVP@C manifested better rate capability and cycling stability than the bulks were attributed to the composite's highly stable framework, porous hollow nanosphere structure, and in situ surface carbon coating. Additionally, Wang et al. applied a template-free ultrasonic spray pyrolysis process for the scalable synthesis of NVP/C porous hollow spheres (Fig. 4e and f), whereas irregular bulk particles were produced by the sol-gel method. ${ }^{61}$ As shown in Fig. $4 \mathrm{~g}$ and $\mathrm{h}$, the rate capability and cycling stability of the porous hollow NVP/C composite prepared via spray pyrolysis were higher than those of its bulk particle counterpart produced by the sol-gel method, which indicates that the feasible and controllable spray pyrolysis method is more suitable for large-scale production of high performance hollow structured cathode materials. 


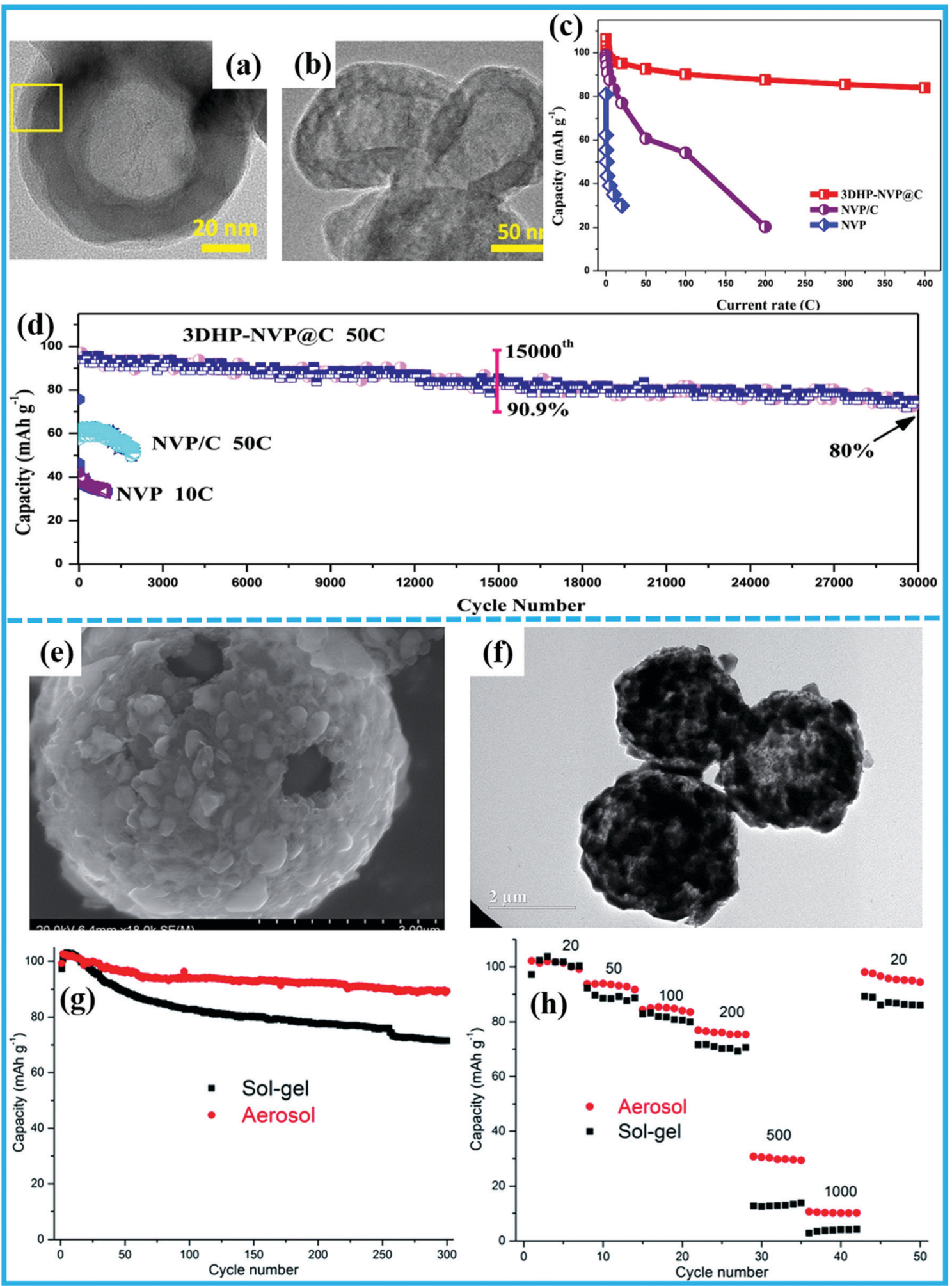

Fig. 4 (a) TEM image. (b) High-resolution TEM (HRTEM) image (of the rectangle in (a)) of an individual hollow 3DHP-NVP@C nanosphere. (c and d) Comparison of rate performance and high-rate stability of 3DHP-NVP@C with NVP and NVP/C. ${ }^{60}$ (Reprinted with permission from Elsevier. Copyright 2017.) (e) SEM image and (f) TEM image of the aerosol synthesized $\mathrm{Na}_{3} \mathrm{~V}_{2}\left(\mathrm{PO}_{4}\right)_{3} / \mathrm{C}$ composite. (g) Rate and (h) cycling performances of the NVP/C composite prepared by spray pyrolysis (SP) and sol-gel processes. ${ }^{61}$ (Reprinted with permission from The Royal Society of Chemistry. Copyright 2015.)

Similarly, $\mathrm{NaFePO}_{4}$ has the same issues of low electronic conductivity. As an analogue of $\mathrm{LiFePO}_{4}$, designing hollow micro-/nanostructured $\mathrm{NaFePO}_{4}$ cathode materials can be a very effective way to achieve high sodium storage performance. 
Recently, Tong et al. prepared hollow amorphous $\mathrm{NaFePO}_{4}$ nanospheres on a large scale by a simple in situ hard template process, and they proposed the possible formation mechanism of the hollow nanospheres. ${ }^{62}$ Firstly, the Fe nanospheres as a hard template can be formed by heating iron(II) stearate, and then the Fe nanospheres were further reacted with $\mathrm{NaH}_{2} \mathrm{PO}_{4}$ to obtain the hollow structured $\mathrm{NaFePO}_{4}$ (Fig. 5a). The as-prepared $\mathrm{NaFePO}_{4}$ composite exhibited exceptional performance with an excellent rate capability at $10 \mathrm{C}$ and ultrastable capacity retention over 300 cycles (Fig. 5b and c). The outstanding electrochemical properties of the hollow amorphous $\mathrm{NaFePO}_{4}$ nanospheres were attributed to its unique hollow structure, which significantly improved the ionic and electronic transport and the de-intercalation/ intercalation kinetics of $\mathrm{Na}^{+}$ions. Numerous studies have proved that the hollow structured cathodes are crucial for good electrochemical performance. Wang et al. reported carbon-coated porous
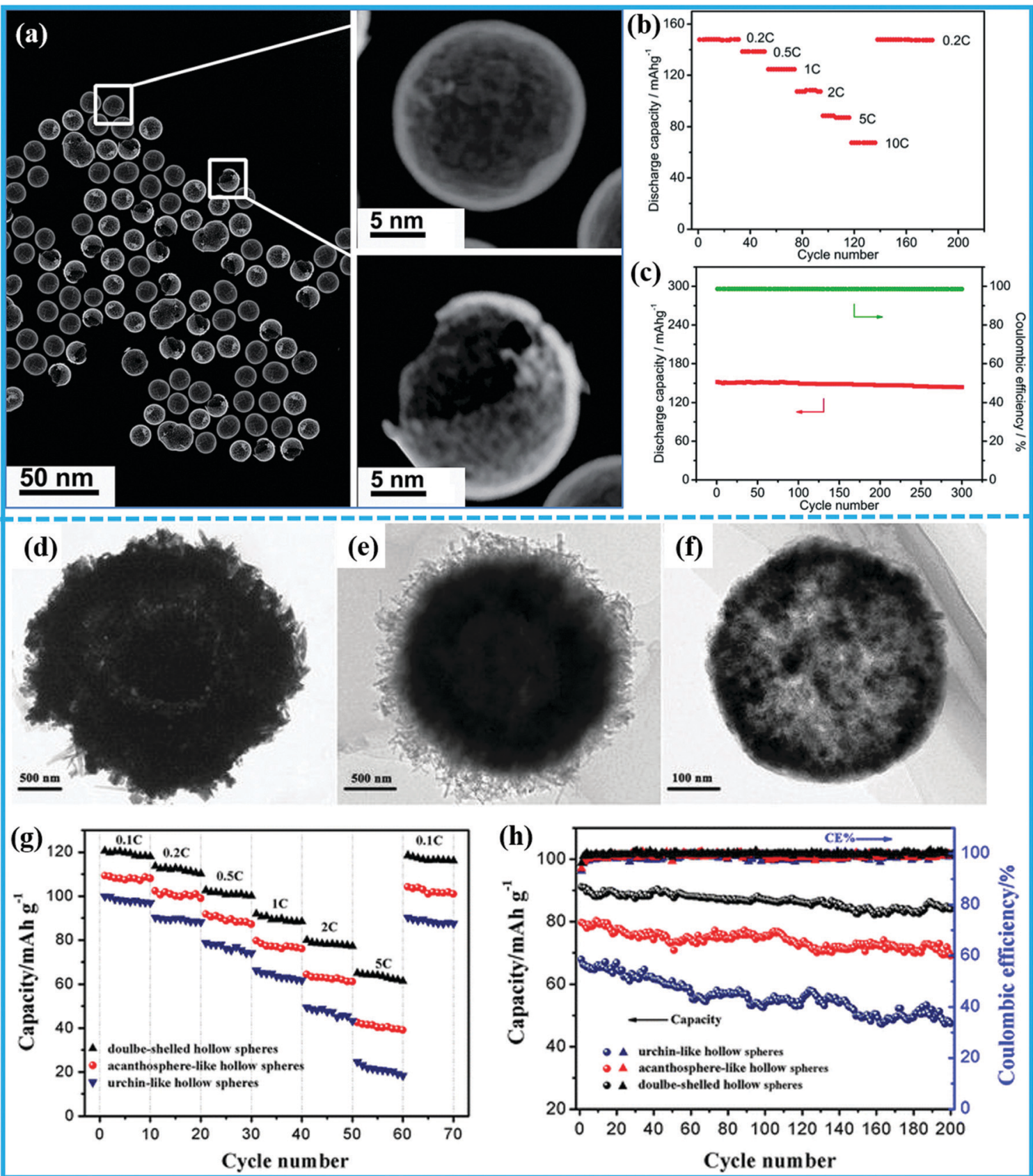

Fig. 5 (a) Low magnification scanning TEM (STEM) image and enlarged STEM images of single nanospheres framed in (a) of the as-prepared hollow amorphous $\mathrm{NaFePO}_{4}$ nanospheres. (b and c) Rate and cycling performances of the hollow amorphous $\mathrm{NaFePO}_{4}$ nanospheres. ${ }^{62}$ (Reprinted with permission from The Royal Society of Chemistry. Copyright 2015.) (d) TEM images of the as-synthesized urchin-like hollow $\mathrm{Na}_{2} \mathrm{FePO}{ }_{4} \mathrm{~F} / \mathrm{C}$ sample. (e) The acanthosphere-like hollow $\mathrm{Na}_{2} \mathrm{FePO}_{4} \mathrm{~F} / \mathrm{C}$ sample, and (f) the double-shelled hollow $\mathrm{Na}_{2} \mathrm{FePO}_{4} \mathrm{~F} / \mathrm{C}$ sample. (g and h) Rate and cycling performances of the urchin-like hollow $\mathrm{Na}_{2} \mathrm{FePO}_{4} \mathrm{~F} / \mathrm{C}$, acanthosphere-like hollow $\mathrm{Na}_{2} \mathrm{FePO}_{4} \mathrm{~F} / \mathrm{C}$, and double-shelled hollow $\mathrm{Na}_{2} \mathrm{FePO}_{4} \mathrm{~F} / \mathrm{C}$ samples. ${ }^{65}$ (Reprinted with permission from Springer, Copyright 2018.) 
hollow $\mathrm{Na}_{2} \mathrm{FePO}_{4} \mathrm{~F}$ synthesized by a one-step template-free ultrasonic spray pyrolysis process. ${ }^{63}$ Benefiting from its unique porous hollow structure, the electrochemical reaction can take place on both the outside and inside surfaces and in the pores. After 750 cycles at $1 \mathrm{C}, \mathrm{Na}_{2} \mathrm{FePO}_{4} \mathrm{~F} / \mathrm{C}$ cathodes can still provide a high capacity of $60 \mathrm{~mA} \mathrm{~h} \mathrm{~g}^{-1}$, showing excellent Na storage performance. Additionally, uniform hierarchical $\mathrm{Na}_{3} \mathrm{~V}_{1.95} \mathrm{Mn}_{0.05}\left(\mathrm{PO}_{4}\right)_{2} \mathrm{~F}_{3} @ \mathrm{C}$ hollow microspheres were prepared by $\mathrm{Xu}$ et $a l .{ }^{64}$ Due to the synergistic effects of the hierarchical hollow microspherical structure, the $\mathrm{Mn}^{2+}$ doping, and the moderate carbon coating, the cathode materials displayed enhanced electrochemical performance. In order to further improve the electrochemical performance, multi-shelled hollow structures were also prepared. Sun's group synthesized hollow structured $\mathrm{Na}_{2} \mathrm{FePO}_{4} \mathrm{~F} / \mathrm{C}$ spheres via a solvothermal method using sodium dodecyl sulfonate (SDS) as the soft template. ${ }^{65}$ Interestingly, when the reaction time was prolonged, the structure of the microspheres gradually changed from urchin-like hollow structures to acanthosphere-like hollow structures and finally to double-shelled hollow structures (Fig. 5d-f). As shown in Fig. 5g, when the three samples experienced a current rate in the range of $5 \mathrm{C}$ to $0.1 \mathrm{C}$, the capacity recovery of the double-shelled hollow $\mathrm{Na}_{2} \mathrm{FePO}_{4} \mathrm{~F} / \mathrm{C}$ was $97.5 \%$, higher than for the acanthosphere-like hollow structure (95.3\%) and the urchin-like hollow structure (89.7\%), exhibiting much better rate capability. Additionally, the double-shelled hollow $\mathrm{Na}_{2} \mathrm{FePO}_{4} \mathrm{~F} / \mathrm{C}$ sample showed more stable cycling performance (92.5\% capacity retention after 200 cycles), much better than for the acanthosphere-like hollow structure (86.5\%) and urchin-like hollow structure (69.9\%) (Fig. 5h). These results demonstrated that double-shelled hollow structures with thin walls can provide more active sites and contact area between the electrode materials and the electrolyte, and thus more outstanding electrochemical properties.

Overall, the problems of slow reaction kinetics and fast capacity decay of polyanionic cathodes can be solved effectively by virtue of hollow micro-/nanostructures because of the shortened ion diffusion length, more contact area with electrolyte and the accommodation of volume changes. However, the challenge is the specific capacity of this kind of cathode is usually not high, and the hollow micro-/nanostructures will further lower the volumetric capacity. Designing a multi-shelled structure may relieve this awkward situation, but the hollow polyanionic cathode materials still have a long way to go for practical applications.

\subsection{Prussian blue analogues}

Prussian blue analogues (PBAs) have diverted the attention of many researchers from other types of materials (metal oxides, metal phosphides, metal sulfides, etc.), due to their facile synthesis method, low-cost raw precursors, and rich redox couples, which contribute to their excellent electrochemical performance. ${ }^{66-68}$ Also, PBAs are regarded as the most promising cathode materials for SIBs, which have been studied in depth by numerous researchers. They still suffer, however, from kinetic problems associated with the solid-state diffusion of $\mathrm{Na}^{+}$ions during charge and discharge processes, which leads to low specific capacity and poor rate performance, critically obstructing their wide-scale applications. ${ }^{69,70}$ Thus, designing hollow micro-/ nanostructured PBAs may be very meaningful for enhancing Na storage performance. The sacrificial-templating method can help with the formation of this unique structure.

Chen et al. applied surface modification and used a hollow architecture to obtain hollow-core-shell heterostructured PBAs with $\mathrm{Mn}^{2+}$ ion and $\mathrm{Ni}^{2+}$ ion co-doping (denoted as HCS-PBMN). ${ }^{71}$ With the assistance of a high-concentration polymer as the hard template, a novel structured HCS-PBMN was formed (Fig. 6a). Through a slow nucleation process, the HCS-PBMN could be prepared with a low defect content and a high sodium content. In addition, the special hollow and core-shell structure of highquality HCS-PBMN contributed significantly to the enhanced Na storage performance (Fig. 6b-d). As regards its electrochemical performance, HCS-PBMN exhibited a remarkable advance compared with other similar materials. The HCS-PBMN showed a high capacity of $123 \mathrm{~mA} \mathrm{~h} \mathrm{~g}^{-1}$ at $50 \mathrm{~mA} \mathrm{~g}^{-1}$, a good rate performance of $52 \mathrm{~mA} \mathrm{~h} \mathrm{~g}^{-1}$ at $3200 \mathrm{~mA} \mathrm{~g}^{-1}$, and a long cycle life with $82.3 \%$ capacity retention after 600 cycles (Fig. 6e and f). This superb electrochemical performance can be attributed not only to the hollow structure, but also to the stable PBN coating layer, in which a large buffer space and high specific surface area were conducive to relieving the volume expansion and improving the ion transfer rate. In addition, the stable PBN coating layer reduced the interface impedance and increased the ion diffusion rate in the bulk. Furthermore, Ma et al. synthesized hierarchical hollow rod-like Mn-doped Prussian blue (R-PB) using $\mathrm{MnO}_{2}$ nanosheets as a selfsacrificial template. ${ }^{72}$ When applying as a cathode for SIBs, it exhibited appealing electrochemical performance, achieving a high discharge capacity of $117.3 \mathrm{~mA} \mathrm{~h} \mathrm{~g}^{-1}$ and a capacity retention of $98.5 \%$ after 200 cycles at $1 \mathrm{C}$. The enhanced discharge capacity and cycling stability of R-PB might be ascribed to the positive effects of the doped-Mn ions and the hierarchical hollow structure of R-PB.

Wang et al. reported hierarchical Na-rich $\mathrm{Na}_{1.58} \mathrm{Fe}\left[\mathrm{Fe}(\mathrm{CN})_{6}\right]_{0.92}$ hollow nanospheres with enhanced electrochemical performance. ${ }^{73}$ A schematic illustration of their synthesis is shown in Fig. 6g. The $\mathrm{Na}_{1.58} \mathrm{Fe}\left[\mathrm{Fe}(\mathrm{CN})_{6}\right]_{0.92}$ hollow nanospheres were prepared via a facile hydrothermal process utilizing reduced $\mathrm{Fe}^{\mathrm{II}} \mathrm{O}_{x}$ as a selfsacrificial template with the assistance of ascorbic acid as a reducing agent. $\mathrm{Na}_{1.58} \mathrm{Fe}\left[\mathrm{Fe}(\mathrm{CN})_{6}\right]_{0.92}$ hollow nanospheres with diameters of about $200 \mathrm{~nm}$ were obtained, as shown in the TEM image in Fig. 6h. Compared with the traditional Na-rich $\mathrm{Na}_{1.58} \mathrm{Fe}\left[\mathrm{Fe}(\mathrm{CN})_{6}\right]_{0.92}$ nanocube morphology, the hollow nanospheres possessed more unique features. For example, the hierarchical architecture had a larger surface area, thus introducing more active sites for the transport of electrons and $\mathrm{Na}^{+}$ions. Furthermore, the hollow structure can buffer the volume changes during insertion/extraction of $\mathrm{Na}^{+}$ions, thus ensuring structural stability. Thanks to these unique characteristics, the as-prepared $\mathrm{Na}_{1.58} \mathrm{Fe}\left[\mathrm{Fe}(\mathrm{CN})_{6}\right]_{0.92}$ nanosphere electrodes delivered an initial charge capacity of $133 \mathrm{~mA} \mathrm{~h} \mathrm{~g}{ }^{-1}$ and discharge capacity of $142 \mathrm{~mA} \mathrm{~h} \mathrm{~g}^{-1}$, corresponding to an extraction of $\sim 1.4 \mathrm{Na}$ and insertion of $\sim 1.5 \mathrm{Na}$ per formula unit, respectively. A capacity of $76 \mathrm{~mA} \mathrm{~h} \mathrm{~g}^{-1}$ could be obtained even at a current density of 10C, indicating superior rate capability (Fig. 6i). Moreover, the 

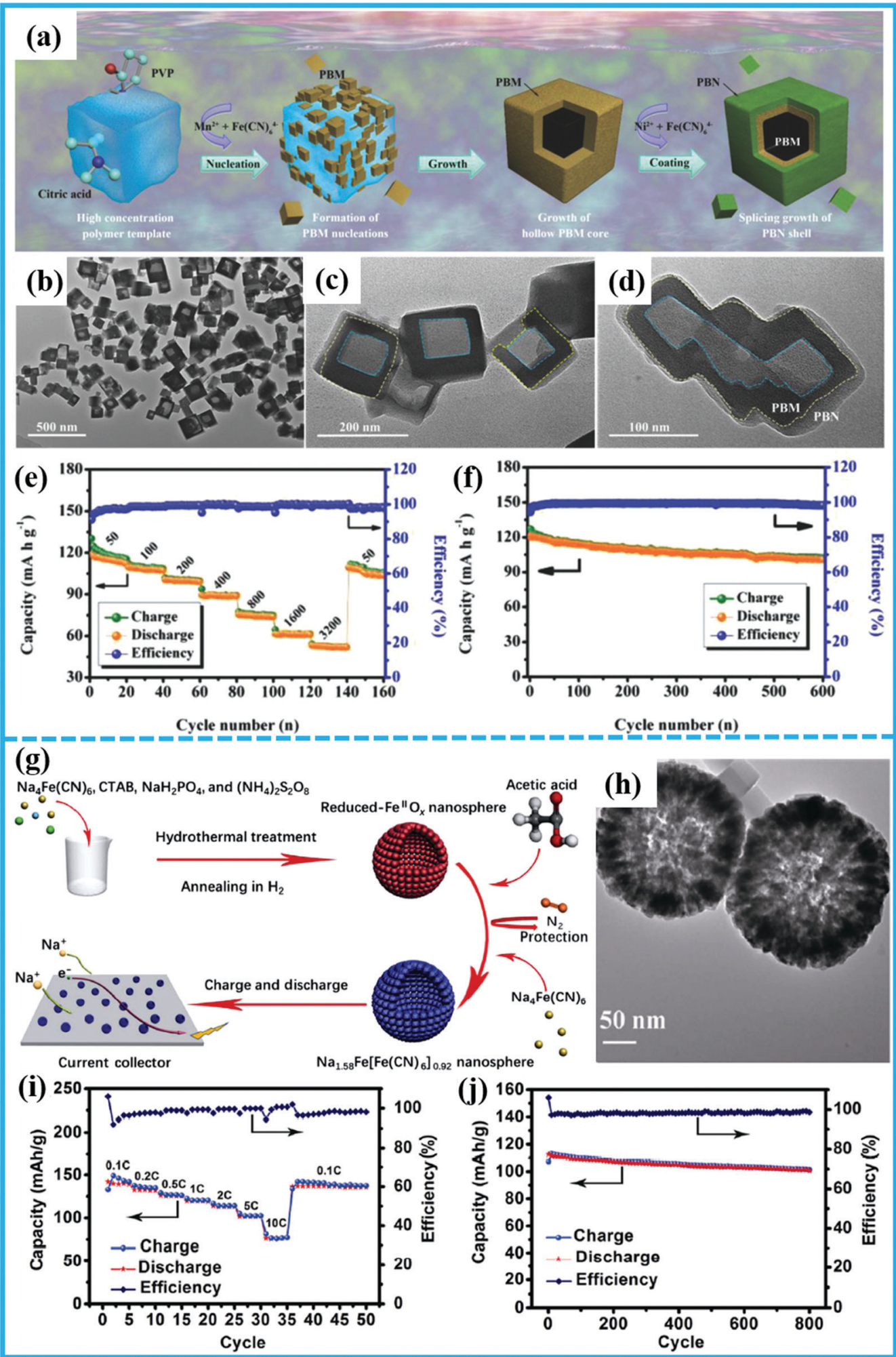

Fig. 6 (a) Schematic illustration of the formation process of the regular heterogeneous HCS-PBMN structure. (b-d) TEM images at different magnifications of HCS-PBMN samples. (e) Rate performance of HCS-PBMN electrodes at various rates (current density: $\mathrm{mA}^{-1}$ ). (f) Long-term cycling performance of HCS-PBMN electrodes measured at a current density of $50 \mathrm{~mA} \mathrm{~g}{ }^{-1} \cdot{ }^{71}$ (Reprinted with permission from Wiley-VCH Verlag Gmbh. Copyright 2018.) (g) Schematic illustration of the synthesis and the discharge mechanism of $\mathrm{Na}_{1.58} \mathrm{Fe}\left[\mathrm{Fe}(\mathrm{CN})_{6}\right]_{0.92}$ hollow nanosphere electrodes. (h) TEM image of $\mathrm{Na}_{1.58} \mathrm{Fe}\left[\mathrm{Fe}(\mathrm{CN})_{6}\right]_{0.92}$ hollow nanospheres. (i) Rate and (j) cycling performances of the $\mathrm{Na}_{1.58} \mathrm{Fe}\left[\mathrm{Fe}(\mathrm{CN})_{6}\right]_{0.92}$ nanosphere electrode. ${ }^{73}$ (Reprinted with permission from Springer. Copyright 2018.). 
cycling performance was also enhanced, with $90 \%$ capacity retention even after 800 cycles at 2C (Fig. 6j).

Currently, the main obstacles of PBAs are their poor electrical conductivity and slow $\mathrm{Na}^{+}$ion diffusion. From the above reports, hollow micro-/nanostructures display superior advantages through improving the reaction kinetics and buffering the volume changes, thus, the rate and cycling performance can be enhanced. Furthermore, if more attention is paid to the increase of tap density, highperformance PBAs with hollow micro-/nanostructures will exhibit great commercialization prospects.

\subsection{Organic compounds}

Organic compounds have been developed as promising substitutes for inorganic cathodes in rechargeable SIBs due to their high theoretical capacities, rapid reaction kinetics, mechanical flexibility, environmental friendliness, and structural diversity. ${ }^{74-76}$ Because of the intrinsic electrically insulating properties of conjugated carbonyl polymers, it is a great challenge to simultaneously achieve high capacity, high rate capability, and long cycle life. ${ }^{12,75}$ Therefore, constructing hollow micro-/nanostructured composites is expected to be an effective way to obtain higher performance. The sacrificialtemplating method has been used to construct hollow micro-/ nanostructured organic compounds.

For example, Cao et al. reported a facile and controllable sacrificial-template strategy combined with the electrospinning method to fabricate polyaniline hollow nanofibers (PANI-HNFs) with different diameters and wall sizes (Fig. 7a). ${ }^{77}$ Here, the poly (methyl methacrylate) nanofibers (PMMA) acted as a sacrifice template (Fig. 7b). The PANI was coated on the surfaces of PMMA nanofibers through a polymerization reaction to form coaxial PMMA@PANI nanofibers (Fig. 7c), and after dissolving the PMMA in toluene, the PANI-HNFs were left (Fig. 7d and e). The PANI-HNFs as a cathode material for SIBs exhibited the high charge and discharge capacity of 230 and $180 \mathrm{~mA} \mathrm{~h} \mathrm{~g}{ }^{-1}$ in the initial cycle, respectively (Fig. 7f). What is more, the PANI-HNFs displayed the high rate capability of $70 \mathrm{~mA} \mathrm{~h} \mathrm{~g}{ }^{-1}$ at $8 \mathrm{C}$ (Fig. $7 \mathrm{~g}$ ) and high cycling stability with $73.3 \%$ capacity retention after 1000 cycles (Fig. 7h). In order to better illustrate the advantages of hollow PANI-HNFs, PANI nanoparticles were also synthesized by using a similar chemical oxidative polymerization method but without the addition of PMMA nanofibers. The product showed the granular morphology of agglomerated nanoparticles. They found that the PANI-HNFs exhibited superior rate capacity compared with the PANI nanoparticles. Overall, the PANI-HNF cathode displayed excellent cycling stability and good rate capability, which was mainly due to its unique hollow fiber structure. On the one hand, the unique hollow fiber structure increases the contact area between the cathode material and the electrolyte, and forms good electronic and ionic conductive networks. On the other hand, the numerous voids alleviate volume changes during charging and discharging. Additionally, polypyrrole (PPy) hollow nanospheres with high sodium storage capacity were synthesized using poly(methyl methacrylate) (PMMA) nanospheres as sacrificial templates by Wang's group (Fig. 7i). ${ }^{78}$ The HRTEM image of PPy hollow nanospheres confirmed that the PMMA nanosphere templates can be completely removed through simply washing with acetone and the vacant inner space can be seen clearly from the inset image (Fig. 7j). When the as-prepared PPy hollow nanospheres were used as cathodes for SIBs, they showed a surprisingly high rate capability, with reversible capacities of $100 \mathrm{~mA} \mathrm{~h} \mathrm{~g}^{-1}$ and $69 \mathrm{~mA} \mathrm{~h} \mathrm{~g}^{-1}$ at $20 \mathrm{~mA} \mathrm{~g}^{-1}$ and $320 \mathrm{~mA} \mathrm{~g}^{-1}$, respectively (Fig. 7k). Moreover, exceptional cycling stability was achieved with $78.5 \%$ capacity retention after 1000 cycles under a high current density of $400 \mathrm{~mA} \mathrm{~g}^{-1}$ (Fig. 7l). In general, the solid electrodes are likely to show higher volumetric density than the hollow electrodes, whereas the cycling and rate performance are usually inferior due to the insufficient contact area with the electrolyte and the longer ion diffusion pathways.

All in all, organic compounds applied in SIBs are promising due to their low-cost and environmentally benign organic sources. By constructing hollow micro-/nanostructures, excellent sodium storage capability can be achieved. The low volumetric capacity for polymer cathodes, however, inspires the designing of more complex hollow structures, such as multi-shelled hollow fiber structures. Therefore, multi-shelled hollow polymer electrodes could be developed for high-performance and low-cost SIBs.

\section{Sodium storage mechanism of hollow micro-/nanostructured cathodes}

The hollow micro-/nanostructures have been verified to be very effective in enhancing the electrochemical performance of SIBs by the above numerous reports. Further deep understanding of the sodium storage mechanism can help to realize the advantages of hollow micro-/nanostructures comprehensively.

As the cathode materials of SIBs, most of them adopt the intercalation mechanism based on the reversible insertion/ extraction of sodium ions. For example, from the aforementioned illustration, hierarchical Na-rich $\mathrm{Na}_{1.58} \mathrm{Fe}\left[\mathrm{Fe}(\mathrm{CN})_{6}\right]_{0.92}$ hollow nanospheres exhibit excellent rate and cycling performance. ${ }^{73}$ For the purpose of understanding the superior properties by constructing hollow structures, Wang et al. conducted cyclic voltammetry (CV) tests at various scan rates to calculate the capacity contribution, and found which is dominated by the intercalation process at the peak voltage. While with the increase of scan rates, the capacitive contribution increased gradually. This can explain the outstanding rate capability, which benefited from the increased surface area of $\mathrm{Na}_{1.58} \mathrm{Fe}\left[\mathrm{Fe}(\mathrm{CN})_{6}\right]_{0.92}$ with a hollow nanospherical structure. Furthermore, to investigate the sodium ion insertion/extraction mechanism, they obtained in situ XRD patterns of the electrode during the charge/discharge process and found that the reversible sodium insertion and extraction contributed to its excellent reversibility and cycling performance. Additionally, except for the conventional intercalation reaction mechanism, doping/dedoping reaction mechanisms can also achieve high-performance organic compounds for SIBs. To further understand the mechanism of sodium ion storage in the as-prepared PPy hollow nanospheres, Wang et al. revealed that the PPy hollow nanospheres function through reversible doping/de-doping reactions during the charge/ discharge processes by virtue of the ex situ SEM, TEM, FTIR 

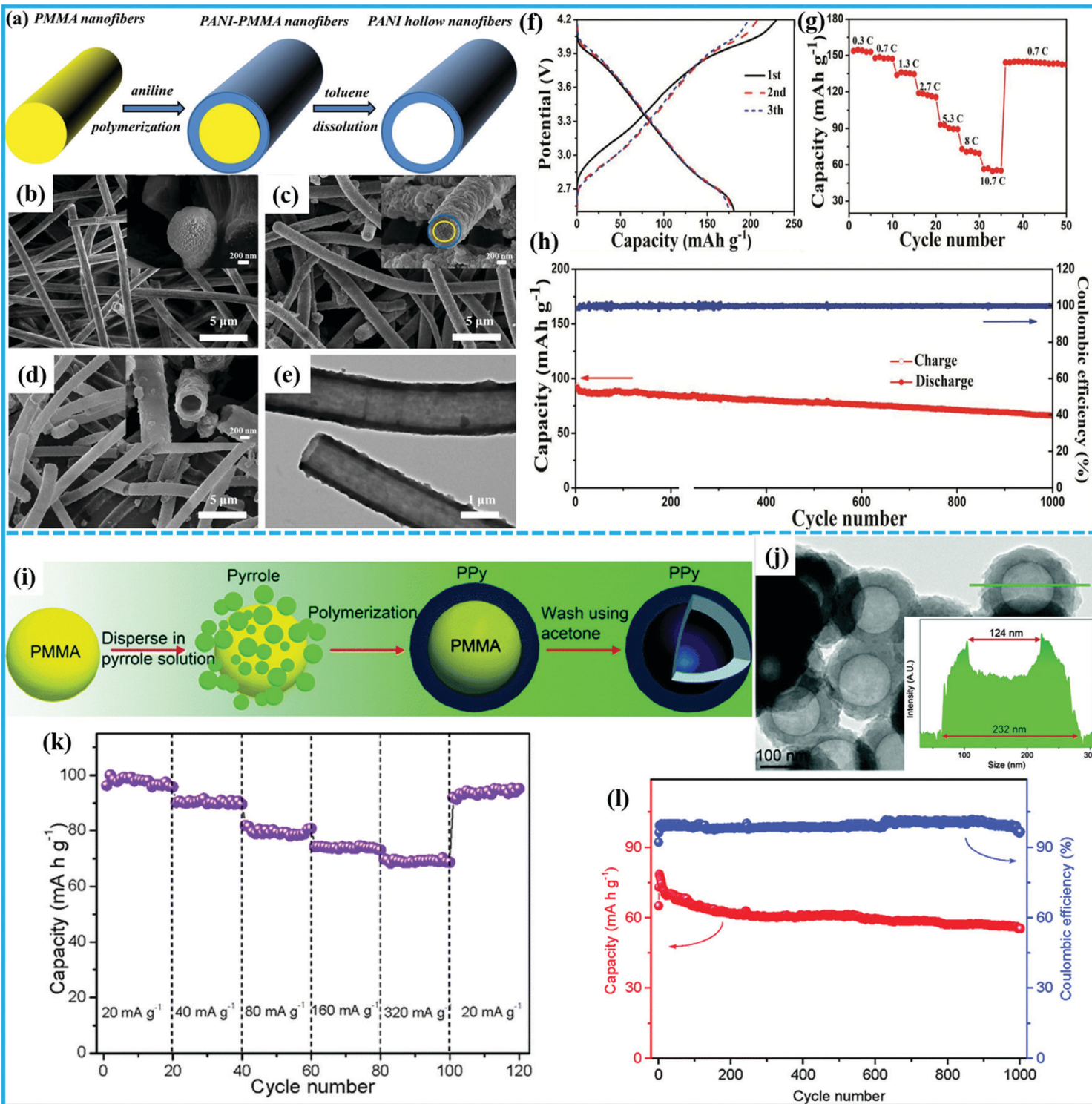
hollow micro-/nanostructures for improving the capacity, stability, and rate capability simultaneously and substantially. Lastly, the sodium storage mechanism of hollow micro-/nanostructured cathodes was introduced.

Nevertheless, there are still some challenges for hollow micro-/nanostructured electrode materials within both the material synthesis and electrochemical performance, and future research is still necessary for various aspects. Firstly, what needs to be considered is that their low volumetric energy density is the main obstacle for the practical application of hollow micro-/ nanostructured cathodes. Thus, seeking to balance the volumetric capacity and energy density is the key to practical hollow structured cathodes in future research. The use of multi-shelled structures may be the best approach to improving the volumetric capacity while retaining all the advantages of hollow structured materials. Secondly, there are still few reports, however, on the use of multi-shelled hollow micro-/nanostructured cathodes for sodium-ion batteries. And the relationship between the unique structural advantages and electrochemical performance of hollow micro-/nanostructures for use in SIBs need to be comprehensively and deeply understood with the help of some advanced in situ characterization and theoretical calculations, such as in situ XRD, SEM, TEM and DFT. Also, it is still difficult to fabricate high-quality multi-shelled hollow materials that satisfy the requirements of energy storage batteries. Finally, the development of large-scale, low-cost fabrication strategies for the preparation of cathodes with a desirable performance is an important challenge. Considering the inferior electronic conductivity of most cathode materials, carbon coating or hybridization with highly conductive materials have already been demonstrated as effective ways to further improve their high rate performance. The volumetric energy density and tap density of the hollow micro-/nanostructures can be relieved by the designing of multi-shelled structures to some extent; however, there are still bottlenecks toward their large-scale commercial applications and extensive exploration is needed in future research.

\section{Conflicts of interest}

There are no conflicts to declare.

\section{Acknowledgements}

This work was financially supported by the National Natural Science Foundation of China (No. 51971124). The authors would like to thank Dr Tania Silver for critical reading of the paper.

\section{References}

1 T. Liu, Y. Zhang, Z. Jiang, X. Zeng, J. Ji, Z. Li, X. Gao, M. Sun, Z. Lin, M. Ling, J. Zheng and C. Liang, Exploring competitive features of stationary sodium ion batteries for electrochemical energy storage, Energy Environ. Sci., 2019, 12, 1512-1533.

2 M. Chen, Q. Liu, S. W. Wang, E. Wang, X. Guo and S. L. Chou, High-Abundance and Low-Cost Metal-Based Cathode Materials for Sodium-Ion Batteries: Problems,
Progress, and Key Technologies, Adv. Energy Mater., 2019, 9, 1803609.

3 J. Deng, W.-B. Luo, S.-L. Chou, H.-K. Liu and S.-X. Dou, Sodium-Ion Batteries: From Academic Research to Practical Commercialization, Adv. Energy Mater., 2018, 8, 1701428.

4 X. Pu, H. Wang, D. Zhao, H. Yang, X. Ai, S. Cao, Z. Chen and Y. Cao, Recent Progress in Rechargeable Sodium-Ion Batteries: toward High-Power Applications, Small, 2019, 15, 1805427.

5 Z. Lin, Q. Xia, W. Wang, W. Li and S. Chou, Recent research progresses in ether-and ester-based electrolytes for sodiumion batteries, InfoMat, 2019, 1, 376-389.

6 L. Zhao, H. Zhao, Z. Du, J. Wang, X. Long and Z. Li, and K. Świerczek, Delicate lattice modulation enables superior $\mathrm{Na}$ storage performance of $\mathrm{Na}_{3} \mathrm{~V}_{2}\left(\mathrm{PO}_{4}\right)_{3}$ as both an anode and cathode material for sodium-ion batteries: understanding the role of calcium substitution for vanadium, J. Mater. Chem. A, 2019, 7, 9807-9814.

7 J. Kim, H. Kim and K. Kang, Conversion-Based Cathode Materials for Rechargeable Sodium Batteries, Adv. Energy Mater., 2018, 8, 1702646.

8 W.-J. Li, C. Han, W. Wang, F. Gebert, S.-L. Chou, H.-K. Liu, X. Zhang and S.-X. Dou, Commercial Prospects of Existing Cathode Materials for Sodium Ion Storage, Adv. Energy Mater., 2017, 7, 1700274.

9 X. Liu, L. Tang, Z. Li, J. Zhang, Q. Xu, H. Liu, Y. Wang, Y. Xia, Y. Cao and X. Ai, An Al-doped high voltage cathode of $\mathrm{Na}_{4} \mathrm{Co}_{3}\left(\mathrm{PO}_{4}\right)_{2} \mathrm{P}_{2} \mathrm{O}_{7}$ enabling highly stable $4 \mathrm{~V}$ full sodiumion batteries, J. Mater. Chem. A, 2019, 7, 18940-18949.

10 W. Shen, C. Wang, Q. Xu, H. Liu and Y. Wang, NitrogenDoping-Induced Defects of a Carbon Coating Layer Facilitate Na-Storage in Electrode Materials, Adv. Energy Mater., 2015, 5, 1400982.

11 S. Liu, L. Wang, J. Liu, M. Zhou, Q. Nian, Y. Feng, Z. Tao and L. Shao, $\mathrm{Na}_{3} \mathrm{~V}_{2}\left(\mathrm{PO}_{4}\right)_{2} \mathrm{~F}_{3}$-SWCNT: a high voltage cathode for non-aqueous and aqueous sodium-ion batteries, J. Mater. Chem. A, 2019, 7, 248-256.

12 Y. Liang, W. H. Lai, Z. Miao and S. L. Chou, Nanocomposite Materials for the Sodium-Ion Battery: A Review, Small, 2018, 14, 1702514.

13 L. Wu, Y. Hu, X. Zhang, J. Liu, X. Zhu and S. Zhong, Synthesis of carbon-coated $\mathrm{Na}_{2} \mathrm{MnPO}_{4} \mathrm{~F}$ hollow spheres as a potential cathode material for Na-ion batteries, J. Power Sources, 2018, 374, 40-47.

14 K. Naoi, K. Kisu, E. Iwama, S. Nakashima, Y. Sakai, Y. Orikasa, P. Leone, N. Dupré, T. Brousse, P. Rozier, W. Naoi and P. Simon, Ultrafast charge-discharge characteristics of a nanosized core-shell structured $\mathrm{LiFePO}_{4}$ material for hybrid supercapacitor applications, Energy Environ. Sci., 2016, 9, 2143-2151.

15 W.-H. Lai, Y.-X. Wang, Y. Wang, M. Wu, J.-Z. Wang, H.-K. Liu, S.-L. Chou, J. Chen and S.-X. Dou, Morphology tuning of inorganic nanomaterials grown by precipitation through control of electrolytic dissociation and supersaturation, Nat. Chem., 2019, 11, 695-701.

16 Y. Xu, W. Shen, A. Zhang, H. Liu and Z. Ma, Template-free hydrothermal synthesis of $\mathrm{Li}_{2} \mathrm{FeSiO}_{4}$ hollow spheres as 
cathode materials for lithium-ion batteries, J. Mater. Chem. A, 2014, 2, 12982-12990.

17 Y. Jiang, Z. Yang, W. Luo, X. Hu and Y. Huang, Hollow $0.3 \mathrm{Li}_{2} \mathrm{MnO}_{3} \cdot 0.7 \mathrm{LiNi}_{0.5} \mathrm{Mn}_{0.5} \mathrm{O}_{2}$ microspheres as a highperformance cathode material for lithium-ion batteries, Phys. Chem. Chem. Phys., 2013, 15, 2954-2960.

18 J. Li, C. Cao, X. Xu, Y. Zhu and R. Yao, $\mathrm{LiNi}_{1 / 3} \mathrm{Co}_{1 / 3} \mathrm{Mn}_{1 / 3} \mathrm{O}_{2}$ hollow nano-micro hierarchical microspheres with enhanced performances as cathodes for lithium-ion batteries, J. Mater. Chem. A, 2013, 1, 11848-11852.

19 F. Xie, L. Zhang, C. Ye, M. Jaroniec and S. Z. Qiao, The Application of Hollow Structured Anodes for Sodium-Ion Batteries: From Simple to Complex Systems, Adv. Mater., 2019, 31, 1800492.

20 J. Wang, H. Tang, H. Wang, R. Yu and D. Wang, Multishelled hollow micro-/nanostructures: promising platforms for lithium-ion batteries, Mater. Chem. Front., 2017, 1, 414-430.

21 X. Zhao, J. Wang, R. Yu and D. Wang, Construction of Multishelled Binary Metal Oxides via Coabsorption of Positive and Negative Ions as a Superior Cathode for SodiumIon Batteries, J. Am. Chem. Soc., 2018, 140, 17114-17119.

22 J. Wang, H. Tang, L. Zhang, H. Ren, R. Yu, Q. Jin, J. Qi, D. Mao, M. Yang, Y. Wang, P. Liu, Y. Zhang, Y. Wen, L. Gu, G. Ma, Z. Su, Z. Tang, H. Zhao and D. Wang, Multi-shelled metal oxides prepared via an anion-adsorption mechanism for lithium-ion batteries, Nat. Energy, 2016, 1, 16050.

23 C. Dong, J. Liang, Y. He, C. Li, X. Chen, L. Guo, F. Tian, Y. Qian and L. Xu, $\mathrm{NiS}_{1.03}$ Hollow Spheres and Cages as Superhigh Rate Capacity and Stable Anode Materials for Half/Full Sodium-Ion Batteries, ACS Nano, 2018, 12, 8277-8287.

24 F. Xie, L. Zhang, D. Su, M. Jaroniec and S.-Z. Qiao, $\mathrm{Na}_{2} \mathrm{Ti}_{3} \mathrm{O}_{7} @$ N-Doped Carbon Hollow Spheres for Sodium-Ion Batteries with Excellent Rate Performance, Adv. Mater., 2017, 29, 1700989.

25 F. Xie, L. Zhang, Q. Gu, D. Chao, M. Jaroniec and S.-Z. Qiao, Multi-shell hollow structured $\mathrm{Sb}_{2} \mathrm{~S}_{3}$ for sodium-ion batteries with enhanced energy density, Nano Energy, 2019, 60, 591-599.

26 X. Q. Zhang, Y. C. Zhao, C. G. Wang, X. Li, J. D. Liu, G. H. Yue and Z. D. Zhou, Facile synthesis of hollow urchin-like $\mathrm{NiCo}_{2} \mathrm{O}_{4}$ microspheres for high-performance sodium-ion batteries, J. Mater. Sci., 2016, 51, 9296-9305.

27 C. C. Nguyen, N. N. Vu and T.-O. Do, Recent advances in the development of sunlight-driven hollow structure photocatalysts and their applications, J. Mater. Chem. A, 2015, 3, 18345-18359.

28 S. Li, A. Pasc, V. Fierro and A. Celzard, Hollow carbon spheres, synthesis and applications-a review, J. Mater. Chem. A, 2016, 4, 12686-12713.

29 X. Zhao, J. Zhu, W. Cai, M. Xiao, L. Liang, C. Liu and W. Xing, Pt-Pb hollow sphere networks: self-sacrifice-templating method and enhanced activity for formic acid electrooxidation, RSC Adv., 2013, 3, 1763-1767.

30 X. Zhou, J. Tian, Q. Wu, J. Hu and C. Li, N/O dual-doped hollow carbon microspheres constructed by holey nanosheet shells as large-grain cathode host for high loading Li-S batteries, Energy Storage Mater., 2019, 24, 644-654.
31 X. W. Lou, L. A. Archer and Z. Yang, Hollow Micro-/Nanostructures: Synthesis and Applications, Adv. Mater., 2008, 20, 3987-4019.

32 X. Lai, J. E. Halpert and D. Wang, Recent advances in micro-/ nano-structured hollow spheres for energy applications: From simple to complex systems, Energy Environ. Sci., 2012, 5, 5604-5618.

33 Y. Yue, A. J. Binder, B. Guo, Z. Zhang, Z. A. Qiao, C. Tian and S. Dai, Mesoporous Prussian Blue Analogues: Template-Free Synthesis and Sodium-Ion Battery Applications, Angew. Chem., Int. Ed., 2014, 53, 3134-3137.

34 F. Han, C. Y. Jun Tan and Z. Gao, Template-free formation of carbon nanotube-supported cobalt sulfide@carbon hollow nanoparticles for stable and fast sodium ion storage, J. Power Sources, 2017, 339, 41-50.

35 X. Jing, Y. Zhang, H. Jiang, Y. Cheng, N. Xing and C. Meng, Facile template-free fabrication of hierarchical $\mathrm{V}_{2} \mathrm{O}_{5}$ hollow spheres with excellent charge storage performance for symmetric and hybrid supercapacitor devices, J. Alloys Compd., 2018, 763, 180-191.

36 H. Tong, Y. Xu, X. Cheng, X. Zhang, S. Gao, H. Zhao and L. Huo, One-pot solvothermal synthesis of hierarchical $\mathrm{WO}_{3}$ hollow microspheres with superior lithium ion battery anode performance, Electrochim. Acta, 2016, 210, 147-154.

37 F. Ghani, A. Raza, D. Kyung, H.-S. Kim, J. Lim and I. W. Nah, Optimization of synthesis conditions of high-tap density $\mathrm{FeVO}_{4}$ hollow microspheres via spray pyrolysis for lithiumion batteries, Appl. Surf. Sci., 2019, 497, 143718.

38 F. Wang, J. Wang, H. Ren, H. Tang, R. Yu and D. Wang, Multi-shelled $\mathrm{LiMn}_{2} \mathrm{O}_{4}$ hollow microspheres as superior cathode materials for lithium-ion batteries, Inorg. Chem. Front., 2016, 3, 365-369.

39 L. Zhou, D. Zhao and X. Lou, $\mathrm{LiNi}_{0.5} \mathrm{Mn}_{1.5} \mathrm{O}_{4}$ Hollow Structures as High-Performance Cathodes for Lithium-Ion Batteries, Angew. Chem., Int. Ed., 2012, 51, 239-241.

40 S. Yang, M. Hu, L. Xi, R. Ma, Y. Dong and C. Y. Chung, Solvothermal Synthesis of Monodisperse $\mathrm{LiFePO}_{4}$ Micro Hollow Spheres as High Performance Cathode Material for Lithium Ion Batteries, ACS Appl. Mater. Interfaces, 2013, 5, 8961-8967.

41 C. Luo, A. Langrock, X. Fan, Y. Liang and C. Wang, P2-type transition metal oxides for high performance $\mathrm{Na}$-ion battery cathodes, J. Mater. Chem. A, 2017, 5, 18214-18220.

42 E. Talaie, S. Y. Kim, N. Chen and L. F. Nazar, Structural Evolution and Redox Processes Involved in the Electrochemical Cycling of $\mathrm{P} 2-\mathrm{Na}_{0.67}\left[\mathrm{Mn}_{0.66} \mathrm{Fe}_{0.20} \mathrm{Cu}_{0.14}\right] \mathrm{O}_{2}$, Chem. Mater., 2017, 29, 6684-6697.

43 L. Wang, Y.-G. Sun, L.-L. Hu, J.-Y. Piao, J. Guo, A. Manthiram, J. Ma and A.-M. Cao, Copper-substituted $\mathrm{Na}_{0.67} \mathrm{Ni}_{0.3-x} \mathrm{Cu}_{x}-$ $\mathrm{Mn}_{0.7} \mathrm{O}_{2}$ cathode materials for sodium-ion batteries with suppressed P2-O2 phase transition, J. Mater. Chem. A, 2017, 5, 8752-8761.

44 P.-F. Wang, Y. You, Y.-X. Yin and Y.-G. Guo, Layered Oxide Cathodes for Sodium-Ion Batteries: Phase Transition, Air Stability, and Performance, Adv. Energy Mater., 2018, 8, 1701912. 
45 J. Shao, Y. Ding, X. Li, Z. Wan, C. Wu, J. Yang, Q. Qu and $\mathrm{H}$. Zheng, Low crystallinity VOOH hollow microspheres as an outstanding high-rate and long-life cathode for sodium ion batteries, J. Mater. Chem. A, 2013, 1, 12404-12408.

46 D. W. Su, S. X. Dou and G. X. Wang, Hierarchical orthorhombic $\mathrm{V}_{2} \mathrm{O}_{5}$ hollow nanospheres as high performance cathode materials for sodium-ion batteries, J. Mater. Chem. A, 2014, 2, 11185-11194.

47 Y. Liu, Y. Qiao, X. Lou, X. Zhang, W. Zhang and Y. Huang, Hollow $\mathrm{K}_{0.27} \mathrm{MnO}_{2}$ Nanospheres as Cathode for HighPerformance Aqueous Sodium Ion Batteries, ACS Appl. Mater. Interfaces, 2016, 8, 14564-14571.

48 D. Lu, Z. Yao, Y. Zhong, X. Wang, X. Xia, C. Gu, J. Wu and J. Tu, Polypyrrole-Coated Sodium Manganate Hollow Microspheres as a Superior Cathode for Sodium Ion Batteries, ACS Appl. Mater. Interfaces, 2019, 11, 15630-15637.

49 Y. Fang, J. Zhang, L. Xiao, X. Ai, Y. Cao and H. Yang, Phosphate Framework Electrode Materials for Sodium Ion Batteries, Adv. Sci., 2017, 4, 1600392.

50 M. Chen, D. Cortie, Z. Hu, H. Jin, S. Wang, Q. Gu, W. Hua, E. Wang, W. Lai, L. Chen, S.-L. Chou, X.-L. Wang and S.-X. Dou, A Novel Graphene Oxide Wrapped $\mathrm{Na}_{2} \mathrm{Fe}_{2}\left(\mathrm{SO}_{4}\right)_{3} /$ C Cathode Composite for Long Life and High Energy Density Sodium-Ion Batteries, Adv. Energy Mater., 2018, 8, 1800944.

51 C. Fang, Y. Huang, W. Zhang, J. Han, Z. Deng, Y. Cao and H. Yang, Routes to High Energy Cathodes of Sodium-Ion Batteries, Adv. Energy Mater., 2016, 6, 1501727.

52 S.-P. Guo, J.-C. Li, Q.-T. Xu, Z. Ma and H.-G. Xue, Recent achievements on polyanion-type compounds for sodium-ion batteries: Syntheses, crystal chemistry and electrochemical performance, J. Power Sources, 2017, 361, 285-299.

53 S. Chen, C. Wu, L. Shen, C. Zhu, Y. Huang, K. Xi, J. Maier and Y. Yu, Challenges and Perspectives for NASICON-Type Electrode Materials for Advanced Sodium-Ion Batteries, Adv. Mater., 2017, 29, 1700431.

54 Q. Ni, Y. Bai, F. Wu and C. Wu, Polyanion-Type Electrode Materials for Sodium-Ion Batteries, Adv. Sci., 2017, 4, 1600275.

55 P. Hu, X. Wang, J. Ma, Z. Zhang, J. He, X. Wang, S. Shi, G. Cui and L. Chen, $\mathrm{NaV}_{3}\left(\mathrm{PO}_{4}\right)_{3} / \mathrm{C}$ nanocomposite as novel anode material for Na-ion batteries with high stability, Nano Energy, 2016, 26, 382-391.

56 Q. Zhu, X. Chang, N. Sun, R. Chen, Y. Zhao, B. Xu and F. Wu, Confined Growth of Nano- $\mathrm{Na}_{3} \mathrm{~V}_{2}\left(\mathrm{PO}_{4}\right)_{3}$ in Porous Carbon Framework for High-Rate Na-Ion Storage, ACS Appl. Mater. Interfaces, 2019, 11, 3107-3115.

57 W. Ren, Z. Zheng, C. Xu, C. Niu, Q. Wei, Q. An, K. Zhao, M. Yan, M. Qin and L. Mai, Self-sacrificed synthesis of three-dimensional $\mathrm{Na}_{3} \mathrm{~V}_{2}\left(\mathrm{PO}_{4}\right)_{3}$ nanofiber network for high-rate sodium-ion full batteries, Nano Energy, 2016, 25, 145-153.

58 E. Wang, M. Chen, X. Liu, Y. Liu, H. Guo, Z. Wu, W. Xiang, B. Zhong, X. Guo, S. Chou and S. X. Dou, Organic CrossLinker Enabling a 3D Porous Skeleton-Supported $\mathrm{Na}_{3} \mathrm{~V}_{2}\left(\mathrm{PO}_{4}\right)_{3} /$ Carbon Composite for High Power Sodium-Ion Battery Cathode, Small Methods, 2019, 3, 1800169.
59 L. Zhao, H. Zhao, X. Long, Z. Li and Z. Du, Superior HighRate and Ultralong-Lifespan $\mathrm{Na}_{3} \mathrm{~V}_{2}\left(\mathrm{PO}_{4}\right)_{3}$ @C Cathode by Enhancing the Conductivity Both in Bulk and on Surface, ACS Appl. Mater. Interfaces, 2018, 10, 35963-35971.

60 T. Wei, G. Yang and C. Wang, Bottom-up assembly of strongly-coupled $\mathrm{Na}_{3} \mathrm{~V}_{2}\left(\mathrm{PO}_{4}\right)_{3} / \mathrm{C}$ into hierarchically porous hollow nanospheres for high-rate and -stable $\mathrm{Na}$-ion storage, Nano Energy, 2017, 39, 363-370.

61 J. Mao, C. Luo, T. Gao, X. Fan and C. Wang, Scalable synthesis of $\mathrm{Na}_{3} \mathrm{~V}_{2}\left(\mathrm{PO}_{4}\right)_{3} / \mathrm{C}$ porous hollow spheres as a cathode for Na-ion batteries, J. Mater. Chem. A, 2015, 3, 10378-10385.

62 C. Li, X. Miao, W. Chu, P. Wu and D. G. Tong, Retracted Article: Hollow amorphous $\mathrm{NaFePO}_{4}$ nanospheres as a highcapacity and high-rate cathode for sodium-ion batteries, J. Mater. Chem. A, 2015, 3, 8265-8271.

63 A. Langrock, Y. Xu, Y. Liu, S. Ehrman, A. Manivannan and C. Wang, Carbon coated hollow $\mathrm{Na}_{2} \mathrm{FePO}_{4} \mathrm{~F}$ spheres for Na-ion battery cathodes, J. Power Sources, 2013, 223, 62-67.

64 Y. Zhang, S. Guo and H. Xu, Synthesis of uniform hierarchical $\mathrm{Na}_{3} \mathrm{~V}_{1.95} \mathrm{Mn}_{0.05}\left(\mathrm{PO}_{4}\right)_{2} \mathrm{~F}_{3} @ \mathrm{C}$ hollow microspheres as a cathode material for sodium-ion batteries, J. Mater. Chem. A, 2018, 6, 4525-4534.

65 R. Ling, S. Cai, D. Xie, W. Shen, X. Hu, Y. Li, S. Hua, Y. Jiang and $\mathrm{X}$. Sun, Double-shelled hollow $\mathrm{Na}_{2} \mathrm{FePO}_{4} \mathrm{~F} / \mathrm{C}$ spheres cathode for high-performance sodium-ion batteries, J. Mater. Sci., 2017, 53, 2735-2747.

66 W. J. Li, C. Han, G. Cheng, S. L. Chou, H. K. Liu and S. X. Dou, Chemical Properties, Structural Properties, and Energy Storage Applications of Prussian Blue Analogues, Small, 2019, 15, 1900470.

67 W. Ren, Z. Zhu, M. Qin, S. Chen, X. Yao, Q. Li, X. Xu, Q. Wei, L. Mai and C. Zhao, Prussian White Hierarchical Nanotubes with Surface-Controlled Charge Storage for Sodium-Ion Batteries, Adv. Funct. Mater., 2019, 29, 1806405.

68 J. Qian, C. Wu, Y. Cao, Z. Ma, Y. Huang, X. Ai and H. Yang, Sodium-Ion Batteries: Prussian Blue Cathode Materials for Sodium-Ion Batteries and Other Ion Batteries, Adv. Energy Mater., 2018, 8, 1870079.

69 Q. Xue, L. Li, Y. Huang, R. Huang, F. Wu and R. Chen, Polypyrrole-Modified Prussian Blue Cathode Material for Potassium Ion Batteries via In Situ Polymerization Coating, ACS Appl. Mater. Interfaces, 2019, 11, 22339-22345.

70 Y. Jiang, S. Yu, B. Wang, Y. Li, W. Sun, Y. Lu, M. Yan, B. Song and S. Dou, Prussian Blue@C Composite as an UltrahighRate and Long-Life Sodium-Ion Battery Cathode, Adv. Funct. Mater., 2016, 26, 5315-5321.

71 Y. Huang, M. Xie, Z. Wang, Y. Jiang, Y. Yao, S. Li, Z. Li, L. Li, F. $\mathrm{Wu}$ and R. Chen, A Chemical Precipitation Method Preparing Hollow-Core-Shell Heterostructures Based on the Prussian Blue Analogs as Cathode for Sodium-Ion Batteries, Small, 2018, 14, 1801246.

72 F. Feng, S. Chen, X. Z. Liao and Z. F. Ma, Hierarchical Hollow Prussian Blue Rods Synthesized via Self-Sacrifice Template as Cathode for High Performance Sodium Ion Battery, Small Methods, 2018, 3, 1800259. 
73 X. Tang, H. Liu, D. Su, P. H. L. Notten and G. Wang, Hierarchical sodium-rich Prussian blue hollow nanospheres as high-performance cathode for sodium-ion batteries, Nano Res., 2018, 11, 3979-3990.

74 Y. Sun, S. Guo and H. Zhou, Exploration of Advanced Electrode Materials for Rechargeable Sodium-Ion Batteries, Adv. Energy Mater., 2019, 9, 1800212.

75 H. Pan, Y.-S. Hu and L. Chen, Room-temperature stationary sodium-ion batteries for large-scale electric energy storage, Energy Environ. Sci., 2013, 6, 2338-2360.
76 S. Wang, L. Wang, Z. Zhu, Z. Hu, Q. Zhao and J. Chen, All Organic Sodium-Ion Batteries with $\mathrm{Na}_{4} \mathrm{C}_{8} \mathrm{H}_{2} \mathrm{O}_{6}$, Angew. Chem., Int. Ed., 2014, 53, 5892-5896.

77 H. Han, H. Lu, X. Jiang, F. Zhong, X. Ai, H. Yang and Y. Cao, Polyaniline hollow nanofibers prepared by controllable sacrificetemplate route as high-performance cathode materials for sodium-ion batteries, Electrochim. Acta, 2019, 301, 352-358.

78 D. Su, J. Zhang, S. Dou and G. Wang, Polypyrrole hollow nanospheres: stable cathode materials for sodium-ion batteries, Chem. Commun., 2015, 51, 16092-16095. 